\title{
BMJ Open Cohort profile: design and methods in the eye and vision consortium of UK Biobank
}

\author{
Sharon Yu Lin Chua, ${ }^{1}$ Dhanes Thomas, ${ }^{1}$ Naomi Allen, ${ }^{2}$ Andrew Lotery, ${ }^{3}$ \\ Parul Desai, ${ }^{1}$ Praveen Patel, ${ }^{1}$ Zaynah Muthy, ${ }^{1}$ Cathie Sudlow, ${ }^{4}$ Tunde Peto, ${ }^{5}$ \\ Peng Tee Khaw, ${ }^{1}$ Paul J Foster, ${ }^{1}$ UK Biobank Eye \& Vision Consortium
}

To cite: Chua SYL, Thomas D, Allen $\mathrm{N}$, et al. Cohort profile: design and methods in the eye and vision consortium of UK Biobank. BMJ Open 2019;9:e025077. doi:10.1136/ bmjopen-2018-025077

- Prepublication history for this paper is available online. To view these files, please visit the journal online (http://dx.doi. org/10.1136/bmjopen-2018025077).

Received 3 July 2018

Revised 1 0ctober 2018

Accepted 11 December 2018

Check for updates

(c) Author(s) (or their employer(s)) 2019. Re-use permitted under CC BY-NC. No commercial re-use. See rights and permissions. Published by BMJ.

${ }^{1}$ NIHR Biomedical Research Centre, Moorfields Eye Hospital NHS Foundation Trust and UCL Institute of Ophthalmology,

London, UK

${ }^{2}$ Nuffield Department of Population Health, University of Oxford, Oxford, UK

${ }^{3}$ Department of Clinical and Experimental Sciences, University of Southampton, Southampton, UK

${ }^{4}$ Centre for Clinical Brain Sciences, University of Edinburgh, Edinburgh, UK ${ }^{5}$ Institute of Clinical Science, Queen's University Belfast

Faculty of Medicine Health and Life Sciences, Belfast, Belfast, UK

Correspondence to

Dr Paul J Foster;

p.foster@ucl.ac.uk

\section{ABSTRACT}

Purpose To describe the rationale, methods and research potential of eye and vision measures available in UK Biobank.

Participants UK Biobank is a large, multisite, prospective cohort study. Extensive lifestyle and health questionnaires, a range of physical measures and collection of biological specimens are collected. The scope of UK Biobank was extended midway through data collection to include assessments of other measures of health, including eyes and vision. The eye assessment at baseline included questionnaires detailing past ophthalmic and family history, measurement of visual acuity, refractive error and keratometry, intraocular pressure (IOP), corneal biomechanics, spectral domain optical coherence tomography (OCT) of the macula and a disc-macula fundus photograph. Since recruitment, UK Biobank has collected accelerometer data and begun multimodal imaging data (including brain, heart and abdominal MRI) in 100000 participants. Dense genotypic data and a panel of 20 biochemistry measures are available, and linkage to medical health records for the full cohort has begun. Findings to date A total of 502665 people aged between 40 and 69 were recruited to participate in UK Biobank. Of these, 117175 took part in baseline assessment of vision, IOP, refraction and keratometry. A subgroup of 67321 underwent OCT and retinal photography. The introduction of eye and vision measures in UK Biobank was accompanied by intensive training, support and a data monitoring quality control process.

Future plans UK Biobank is one of the largest prospective cohorts worldwide with extensive data on ophthalmic diseases and conditions. Data collection is an ongoing process and a repeat of the baseline assessment including the questionnaires, measurements and sample collection will be performed in subsets of 25000 participants every 2-3 years. The depth and breadth of this dataset, coupled with its open-access policy, will create a powerful resource for all researchers to investigate the eye diseases in later life.

\section{INTRODUCTION}

Ageing populations worldwide face an increasing burden of chronic and neurodegenerative diseases, ${ }^{1}$ resulting in substantial health and economic burdens. ${ }^{2}{ }^{3}$ Chronic

\section{Strengths and limitations of this study}

- UK Biobank is the largest prospective cohort with extensive measures on ophthalmic diseases and conditions.

- Repeated physical measures every few years and linkage to National Health Service records will provide valuable information on health outcomes.

- A large number of incident cases of eye diseases in 5 years will allow the detection and quantification of small effect sizes.

A low response rate $(5.5 \%)$.

age-related eye diseases, such as age-related macular degeneration (AMD), diabetic retinopathy (DR) and glaucoma, are leading causes of visual impairment in Western populations. Increased intraocular pressure (IOP) is one of the most significant risk factors for the development ${ }^{4}$ and progression ${ }^{5}$ of glaucoma. A recent study from the UK Biobank demonstrated that factors including diabetes, height, smoking and black ethnicity have different associations with Goldmann-correlated IOP (IOPg) and corneal-compensated IOP (IOPcc). ${ }^{6}$ Hence, suggesting that these factors are related to corneal biomechanical properties. In another UK Biobank study, 67321 participants underwent optical coherence tomography (OCT) imaging of both eyes. ${ }^{7}$ The OCT is a non-invasive imaging system that provides high-resolution, cross-sectional images of the retina, retinal nerve fibre layer (RNFL) and the optic nerve, aiding in the diagnosis and management of eye diseases. ${ }^{8}$ Loss of vision due to eye diseases has a considerable impact on an individual's activities and quality of life. ${ }^{9}{ }^{10}$ Identifying modifiable risk factors of common disabling diseases of later life may help develop preventive strategies. These conditions are often caused by a combination of genetics, environmental and lifestyle factors. Built on a 
foundation laid by the Human Genome Project, ${ }^{11}$ the last decade has seen dramatic advances in the understanding of molecular mechanisms in the human health and disease. A myriad of studies using traditional linkage methods and genome-wide association studies ${ }^{12-14}$ have now raised questions about the role of gene-gene ( $\mathrm{GxG})$ and gene-environment (GxE) interaction in determining disease susceptibility. ${ }^{15} 16$ Extensive information on environment and lifestyle in conjunction with biological samples are crucial to assess GxE interactions.

To avoid the potential for reverse causality and minimise recall bias, exposures should be measured before they are affected by disease or its treatment. Prospective cohorts offer many advantages for assessing the combined effects of genes, environment and lifestyle factors and its association with various health outcomes. The prospective nature of these cohorts allows the exposures to be recorded before the disease onset, and a wide range of diseases to be investigated, including those that may be challenging to study retrospectively. ${ }^{17}$ Furthermore, the overall beneficial and adverse effects of a specific exposure on the lifetime risks of numerous diseases can be examined. Only a small proportion of individuals will develop the disease and the effects of various exposures on disease development are likely to be modest. Hence, to address questions of GxG and GxE interaction, prospective studies need to include a large number of participants, with several hundred thousand participants. ${ }^{18}$ However, there is a lack of large prospective studies at such a scale that allow investigation of risk factors or gene-environmental interaction of eye diseases.

UK Biobank (https://www.ukbiobank.ac.uk/) is a large-scale multisite cohort study, conceived to provide a resource for the scientific community to examine genetic and environmental risk factors for complex diseases of middle and old age in the UK population. UK Biobank has collected extensive baseline questionnaire data, physical measures and biological samples, with comprehensive follow-up and characterisation of many different health outcomes. ${ }^{20}$ Towards the end of the baseline phase, the UK Biobank Steering Committee advised the broadening of the scope of the study to include more detailed examination of participants, including assessment of arterial stiffness, a hearing test, additional cognitive function tests, cardiorespiratory fitness, collection of whole blood and saliva, as well as an examination of eyes and vision. The UK Biobank eye and vision data provide researchers with a unique opportunity to access a very large dataset containing detailed ocular phenotypic information, together with rich biomarker variables, dense genotyping and extensive information on lifestyle variables, medical history and healthcare episodes, thus giving unique research resource. As such, UK Biobank offers comprehensive data to explore novel aetiological associations, risk factors and to make evidence-based recommendations on policy. This report aims to describe the methods and the baseline characteristics of the participants who underwent eye and vision assessment in UK Biobank.

\section{COHORT DESCRIPTION}

\section{Whole UK Biobank cohort}

UK Biobank is a large, multisite, study of 502656 UK residents aged between 40 and 69 years who were registered with the National Health Service (NHS). The overall study protocol (http://www.ukbiobank.ac.uk/ resources/) and protocols for individual tests (http:// biobank.ctsu.ox.ac.uk/crystal/catalogs.cgi) are available online. Briefly, extensive baseline questionnaires and physical measures were obtained from 22 assessment centres between January 2006 and October 2010. ${ }^{20} 21$ This included data on sociodemographics, family history and early life exposures, psychosocial, environmental, lifestyle, environmental and health status, hearing threshold and cognitive function as well as self-reported medical conditions. In addition to the baseline questionnaire, web-based questionnaires were included to obtain data on dietary intake, occupational history, cognitive function, mental health and gastrointestinal symptoms. In addition, mailed triaxial accelerometers will supplement the physical activity data in 100000 participants. ${ }^{20}$

Physical examination included blood pressure, heart rate, hand grip strength, anthropometrics, spirometry, bone density, arterial stiffness, fitness test. Biological samples, including stored blood, urine and saliva samples, were collected to allow many different types of assay (eg, genetic, proteomic, metabolomics, biochemical and haematologic), (https://www.ukbiobank.ac.uk/) 2223 providing a uniquely rich resource for investigating aetiological risk factors and thereby assisting in the prevention and treatment of many different conditions. The UK Biobank Axiom array was used for genotyping and the methods have been described in detail. ${ }^{23}$ Furthermore, UK Biobank launched the world's largest health imaging study in 2014 (www.imaging.ukbiobank.ac.uk) that aims to perform MRI of brain, heart and abdomen, carotid ultrasound and dual-energy X-ray absorptiometry body scans on 100000 participants. ${ }^{24}$ A detailed follow-up of participants over a 20-year period is envisaged through data linkage to national electronic medical records. Thus, linking to NHS will provide valuable information on health outcomes (eg, mortality, cancer registrations, hospital admissions, primary care data, etc).

The key ethics and governance principles relating to UK Biobank are laid out in the Ethics and Governance Framework, ${ }^{22}$ prepared by the project funders. Major funders include Medical Research Council (MRC) and Wellcome Trust, while other funding bodies include Department of Health (DoH), Scottish Government and the Welsh Government, North West Development Agency, British Heart Foundation and Diabetes UK. All participants provided informed consent.

\section{UK Biobank eye and vision subcohort}

Study location

Ocular measurements commenced in late 2009 at six assessment centres as an additional enhancement to the initial baseline measures. The six centres are distributed 
across the UK, including Croydon and Hounslow in Greater London, Liverpool and Sheffield in Northern England, Birmingham in the Midlands and Swansea in Wales. ${ }^{6}$

\section{Examination procedures \\ Questionnaires}

Self-reported eye diseases, including glaucoma, DR and AMD, were obtained from self-administered questionnaires.

\section{Measurements}

The methods and protocol for the ocular examination component were designed by ophthalmologists from Moorfields Eye Hospital (MEH), London, UK. The core funding for the examination was provided by the Wellcome Trust, the MRC and the DoH. Additional support for training, implementation and quality control came from the NIHR Biomedical Research Centre at MEH. All ocular examinations were undertaken by trained personnel to ensure that the ocular measurements were acquired in a stepwise manner using standard operating procedures or instructions, and they had to pass a structured examination before the project started. The entire process including the teaching material was reviewed and moderated by an ophthalmologist from MEH, London, UK. The ocular examinations were conducted without pharmacological mydriasis and took an average time of $11 \mathrm{~min}$ to complete. ${ }^{7}$ Baseline eye examination was conducted from June 2009 to July 2010, subsequently, from August 2012 to June 2013, a subset of approximately 20000 underwent follow-up examination, including all eye measures.

\section{Visual acuity}

Visual acuity (VA) was measured using a logarithm of the minimum angle of resolution (LogMAR) chart (Precision Vision, LaSalle, Illinois, USA) on a computer screen under standard illumination. It follows the British Standards Institute, ${ }^{25}$ and the right eye was measured first. The test was performed with participants wearing the distance refraction at $4 \mathrm{~m}$, or at $1 \mathrm{~m}$ if a participant was unable to read. Participants were asked to read each letter from the top of the chart and down as far as possible. The test was terminated when $\geq 2$ letters are incorrect and recorded as LogMAR VA.

\section{Refraction}

Non-cycloplegic autorefraction was performed using the Tomey RC-5000 Auto Refkeratometer (Tomey, Nagoya, Japan) and the right eye was measured first. For each eye, up to 10 measurements were taken and each measurement had a score between 0 and 9 (smaller scores indicate more reliable measurements). To ensure measurements were reliable, each reading achieved a score of $\leq 4 .{ }^{26}$

\section{Intraocular pressure}

IOP was measured using the Ocular Response Analyzer (ORA) (Reichert, Philadelphia, Pennsylvania, USA). ${ }^{27}$
One measurement was taken for each eye and the right eye was measured first. The ORA uses a rapid pulse air to indent the cornea and an electro-optical system records the corneal deformation. Two applanation measurements are recorded: (1) while the cornea moves inwards, achieving a first applanation state or flattening $\left(\mathrm{P}_{1}\right)$; (2) when the cornea recovers from its slight concave state as the pressure decreases, and the cornea passes through a second applanated state $\left(\mathrm{P}_{2}\right)$. Hence, $\mathrm{P}_{1}$ and $\mathrm{P}_{2}$ are air pressures that correspond with the two applanation states of the cornea. ${ }^{28}$ The average of the 2 ORA pressure values was calibrated against Goldmann applanation tonometer to derive IOPg $(\mathrm{mm} \mathrm{Hg})$ A separate IOPcc reading $\left(\mathrm{IOPcc}=\mathrm{P}_{1}\right.$ and $\left.0.43 * \mathrm{P}_{2}\right)$ was derived to limit the difference before and after laser-assisted in situ keratomileusis (LASIK) surgery and has, therefore, limited influence from corneal biomechanics than those provided by Goldmann applanation tonometer. ${ }^{27} 29$

\section{Corneal hysteresis}

Corneal hysteresis $(\mathrm{CH})$ is considered an indicator of corneal viscous energy damping and is derived as the difference between $\mathrm{P}_{1}$ and $\mathrm{P}_{2}: \mathrm{CH}=\mathrm{P}_{1}$ and $\mathrm{P}_{2} \cdot{ }^{27} 28$

\section{Optical coherence tomography}

OCT images were obtained using a spectral domain OCT 3-dimensional (3D OCT-1000 Mark II, Topcon, Japan). The scans were conducted in a darkened room under standard illumination without pupil dilation using a 3D macular volume scan (512 horizontal A-scans/B-scan; $128 \mathrm{~B}$-scans in a $6 \times 6 \mathrm{~mm}$ raster pattern). The methodology of the OCT imaging has been described previously. $^{730}$

\section{Fundus photography}

Colour photographs of the optic disc and macular were acquired using a Topcon 3D OCT-1000 Mark II system. The Topcon 3D OCT-1000 has a field angle of $45^{\circ}$, a digital zoom (2X, 4X), scanning range of $6 \times 6 \mathrm{~mm}, 4.5 \times 4.5 \mathrm{~mm}, 3 \times 3 \mathrm{~mm}$ and a scanning speed of 18000 A-scans per second. The horizontal and longitudinal (depth) resolutions were $\leq 20 \mu \mathrm{m}$ and $5-6 \mu \mathrm{m}$, respectively. ${ }^{31}$

\section{Data monitoring and quality assessment feedback}

Daily monitoring of data collection was performed by UK Biobank using a custom-designed monitoring software (WACMAN). The WACMAN software monitored the data items collected and allowed individual operator's performance to be reviewed-the number of measurements skipped and the degree to which the data collected by the operator lay within the range of expected values. The performance of the technicians responsible for ophthalmic imaging was monitored to provide feedback to those producing substandard quality images within three working days. This was achieved by grading the first 100 photographs of each technician and at least $5 \%$ of all OCT images. 
502,665 participants in the whole UK Biobank

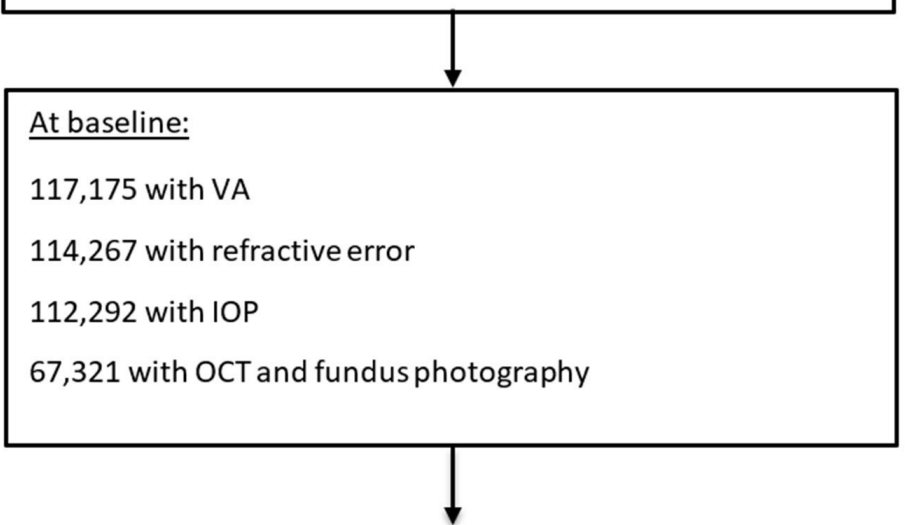

At $1^{\text {st }}$ repeat visit:

20,202 with VA, of which 4,222 had VA measures at both visits.

19,505 with refractive error, of which 4,008 had refractive error measures at both visits.

19,516 with IOP, of which 3,961 had IOP measures at both visits.

17,876 with OCT and fundus photography, of which 2,286 had OCT and fundus photography measures at both visits.

Figure 1 Flow chart of participants with the eye measures at baseline and first repeat visit in the UK Biobank. IOP, intraocular pressure; OCT, optical coherence tomography; VA, visual acuity.

\section{Patient and public involvement}

UK Biobank maintains a website to keep participants and researchers up to date on the study, which contains a news feed (http://www.ukbiobank.ac.uk/news/) and feedback service. In addition, UK Biobank has a twitter feed.

There is an annual scientific meeting which is recorded and available to the public as webcast.

The study was set up by the MRC, DoH and Wellcome Trust with input from major patient representative organisations (British Heart Foundation and Cancer Research UK) http://www.ukbiobank.ac.uk/public-consultation/

\section{Statistical analysis}

The baseline ocular characteristics were analysed and presented as mean $\pm \mathrm{SD}$ for continuous variables and number (\%) for categorical variables. Statistical analyses were performed using STATA software V.13.0 (StataCorp).

\section{RESULTS}

\section{Findings to date}

In total, ocular measures including VA, refraction and IOP data were measured in approximately 117175 people aged 40-69 years. Of these, OCT imaging and fundus photography were performed in $67321(57.5 \%)$ participants. Figure 1 describes the number of participants with eye measures at baseline and first repeat visit. Table 1 describes the baseline characteristics of participants in the total cohort, and among participants with various ocular measurements at baseline and at first repeat visits. Compared with the whole UK Biobank cohort, participants with baseline VA and OCT measures consisted of a higher proportion of Asians, blacks and mixed/ others ethnic groups and had more positive Townsend Deprivation Index. Compared with participants with baseline eye measures, those with repeat visit of VA or OCT data were older, more likely male, of white ethnic background, had the educational level of degree and above, had more negative Townsend Deprivation Index or better socioeconomic status and less likely to smoke.

Table 2 summarises the number of participants completing each test and the summary measures for these tests. The VA and refractive error measures were quite similar at baseline and at the first repeat visits. Mean VA was approximately $0.0 \operatorname{LogMAR}$ at both visits. At both visit, the mean spherical equivalent refraction was -0.3 D. Approximately $60 \%$ of participants were non-myopic, while the proportion of participants with low, moderate and high myopia were 24\%, $11 \%$ and 5\%, respectively. Participants' mean IOP was slightly higher at first repeat visit than at baseline. The mean IOPg ranged from $15.7 \mathrm{~mm} \mathrm{Hg}$ to $16.2 \mathrm{~mm} \mathrm{Hg}$, while IOPcc ranged from $16.0 \mathrm{~mm} \mathrm{Hg}$ to $16.5 \mathrm{~mm} \mathrm{Hg}$. The proportion of participants with ocular hypertension was $12 \%$ at baseline and $16 \%$ at first repeat visit. Projected number of new cases of eye diseases including AMD, cataract and primary open angle glaucoma (POAG) expected to occur among the whole UK Biobank cohort and subcohort during the 


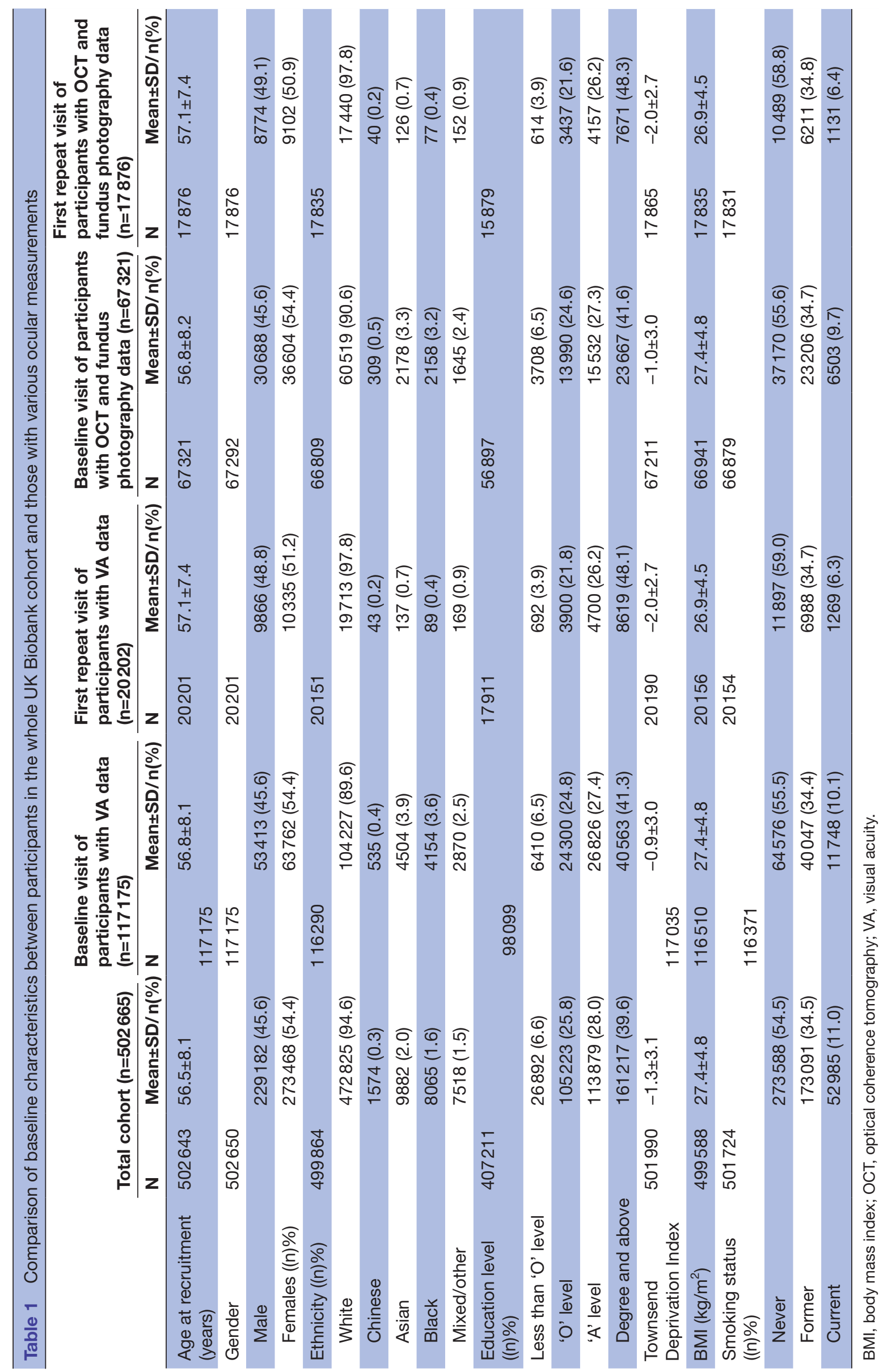


Table 2 Ocular characteristics of participants in the UK Biobank at baseline visit and at the first repeat visit

\begin{tabular}{|c|c|c|c|c|c|}
\hline \multirow[b]{2}{*}{ Type of eye test } & \multirow{2}{*}{$\begin{array}{l}\text { Summary measure } \\
\text { Description }\end{array}$} & \multicolumn{2}{|c|}{ Baseline visit } & \multicolumn{2}{|c|}{ First repeat visit } \\
\hline & & $\mathbf{N}$ & Mean \pm SD/(\%) & $\mathbf{N}$ & Mean \pm SD/(\%) \\
\hline Visual acuity & Mean \pm SD LogMAR in RE & 116068 & $0.03 \pm 0.21$ & 20162 & $0.00 \pm 0.21$ \\
\hline \multirow[t]{5}{*}{ Refraction } & Mean $\pm S D$ spherical equivalent in RE (D) & 114269 & $-0.36 \pm 2.74$ & 19505 & $-0.34 \pm 2.86$ \\
\hline & Mean \pm SD spherical equivalent in LE (D) & 113895 & $-0.30 \pm 2.76$ & 19381 & $-0.31 \pm 2.90$ \\
\hline & No $(\%)$ of low myopes $(\leq-2.99 \mathrm{D})^{*}$ & 27048 & 23.5 & 4656 & 23.6 \\
\hline & No $(\%)$ of moderate myopes $(\leq-3.00 \text { to } \geq-5.99 \mathrm{D})^{\star}$ & 12033 & 10.5 & 2336 & 11.8 \\
\hline & No $(\%)$ of high myopes $(\leq-6.00 \mathrm{D})^{*}$ & 5917 & 5.2 & 1095 & 5.6 \\
\hline \multirow{2}{*}{$\begin{array}{l}\text { Ocular Response } \\
\text { Analyzer }\end{array}$} & Mean \pm SDIOPg in RE (mm Hg) & 112292 & $15.88 \pm 3.97$ & 19515 & $16.19 \pm 4.28$ \\
\hline & Mean \pm SDIOPg in LE $(\mathrm{mm} \mathrm{Hg})$ & 111961 & $15.74 \pm 4.02$ & 19460 & $16.05 \pm 4.30$ \\
\hline
\end{tabular}

*Myopia severity defined from either eye.

†Ocular hypertension defined from either eye.

IOPcc, corneal-compensated intraocular pressure; IOPg, Goldmann-correlated intraocular pressure; LE, left eye; LogMAR, logarithm of the minimum angle of resolution; RE, right eye.

period of 25 years follow-up (table 3 ).$^{32}$ By 2023, the expected number of new cases of any AMD, cataract and POAG were around 11753,107702 and 8704 in the whole cohort, respectively, with around $14 \%$ of these cases

Table 3 Predicted number of new cases of eye diseases expected to occur during the first 25 years of follow-up in UK Biobank

\begin{tabular}{crrrr}
\hline $\begin{array}{l}\text { Type of eye } \\
\text { disease }\end{array}$ & $\mathbf{2 0 1 8}$ & $\mathbf{2 0 2 3}$ & $\mathbf{2 0 2 8}$ & $\mathbf{2 0 3 3}$ \\
\hline \multicolumn{5}{c}{ Whole cohort } \\
\hline AMD & \multicolumn{5}{c}{. } \\
\hline Any AMD & 5455 & 11753 & 22727 & 41205 \\
\hline NV AMD & 3989 & 8584 & 16577 & 30007 \\
GA AMD & 3107 & 6718 & 13030 & 23663 \\
\hline Cataract & 61483 & 107702 & 157499 & 204220 \\
\hline POAG & 5103 & 8704 & 13113 & 18296 \\
\hline \multicolumn{5}{c}{ Ocular subcohort* } \\
\hline
\end{tabular}

\begin{tabular}{lrrrr} 
AMD & & & & \\
Any AMD & 766 & 1649 & 3186 & 5761 \\
NV AMD & 560 & 1204 & 2322 & 4198 \\
GA AMD & 437 & 944 & 1829 & 3317 \\
Cataract & 8593 & 14984 & 21787 & 28093 \\
POAG & 708 & 1207 & 1817 & 2532 \\
\hline
\end{tabular}

Adapted from Desai et al. ${ }^{32}$

*Ocular subcohort who had ophthalmic assessment at baseline, including retinal imaging.

AMD, age-related macular degeneration; GA, geographic atrophy; NV, neovascular; POAG, primary open angle glaucoma. occurring in the ocular subcohort. From 2023 to 2033, the expected number of new cases of any AMD increased by 3.5 times, while the expected number of cataract and POAG increased by two times.

Findings from the UK Biobank eye data showed that first-born individuals were more often myopic than non-first-born, ${ }^{33}$ which confirms previous findings. ${ }^{34} 35$ New findings include the discovery of 112 loci, including 68 novel loci, associated with IOP and the development of POAG. Several loci suggest the importance of angiopoietin-receptor tyrosine kinase (ANG-TEK) in signalling IOP regulation, thus suggesting ANG-TEK to be a therapeutic target. In individuals without neurodegeneration, thinner RNFL was associated with worse cognitive function and more likely to have future cognitive decline. ${ }^{36}$ The use of deep-learning models predicted cardiovascular risk factors such as age (mean absolute error within 3.26 years), gender (area under the curve $(\mathrm{AUC})=0.97$ ), smoking status (AUC $=0.71)$, systolic blood pressure (mean absolute error within $11.23 \mathrm{~mm} \mathrm{Hg}$ ) and major adverse cardiac events $(\mathrm{AUC}=0.70){ }^{37}$

\section{DISCUSSION}

Common age-related eye diseases, including AMD, DR, glaucoma and myopia, are leading causes of visual impairment, ${ }^{38}$ and have both genetic and environmental contributions. Smoking and age are the most consistently observed non-genetic risk factors for AMD,${ }^{39}$ and several established genetic risk factors have been identified. ${ }^{40}$ Significant gene-environmental interactions have been identified for complement factor $\mathrm{H}$ gene and smoking for AMD. ${ }^{42}$ However, limitations exist and generalisability 
of the findings is uncertain. Hence, future prospective studies of larger sample size would help to clarify the issue. The UK is in an ideal position to undertake ambitious 'big data' health sciences research, given the extensive coverage of the NHS and various detailed health record systems. UK Biobank has begun to harness these strengths to deliver epidemiological research at scale. Repeating detailed physical measures every few years in subsets of 20-25 000 participants adds a powerful longitudinal dimension, with health-related outcomes being tracked through linkage to NHS records including death and cancer registers, hospital inpatient and outpatient episodes and primary care. Other health record linkage including data from national mental healthcare, residential history, laboratory and disease audit datasets, National Ophthalmology Database Audit, OpenEyes, Medisoft Ophthalmology, and may also include imaging, cancer screening and dental. ${ }^{20}$ To enhance accurate identification of health outcomes, additional methods such as cross-referencing against NHS case records, imaging and eye data or banked tissues will be used for validation and subclassification.

\section{SCOPE OF EYE DATA}

UK Biobank is among the largest eye and vision datasets globally. By 2023, >11000 incident cases of AMD, >8000 cases of POAG and about 107000 cataract surgeries will have occurred in the whole UK Biobank cohort. ${ }^{32}$ This large number of new cases of eye diseases will provide substantial power for nested case-control studies to detect the main effect OR of 1.3 or higher. ${ }^{43}$ With the rise in ageing population, the rates of chronic eye diseases will increase. However, the rates of undiagnosed eye diseases remain high. Population-based studies reported that at least $50 \%$ of whites, ${ }^{44-47}$ and $55 \%-90 \%$ of Asians ${ }^{4-50}$ have undiagnosed glaucoma. Approximately $70 \%$ of undiagnosed cataracts were reported in $\mathrm{USA}^{51}$ and Singapore. ${ }^{52}$ In addition to undiagnosed eye conditions, people were found to be unaware of their eye conditions. Previous population-based reported that only $5 \%-46 \%$ of those identified as having an eye disease (eg, AMD, ${ }^{53}$ cataract, ${ }^{53}$ glaucoma and $\mathrm{DR},{ }^{54}$ accurately self-reporting their disease). ${ }^{55}$ Hence, linking to electronic health records is essential to ensure accuracy in identification of eye diseases. In UK Biobank, the overall self-reported glaucoma rate was $1.7 \%$ among people aged $40-69$ years. ${ }^{56}$ This rate appears to be lower compared with White populations aged 40 years and older in the USA $(2.08 \%),{ }^{46}$ Australia $(2.0 \%)^{57}$ and Italy $(2.9 \%) .^{58}$

\section{RETINA AND THE CARDIOVASCULAR SYSTEM}

Retinal imaging has provided probably the richest data relating to eyes and vision in UK Biobank. In addition to giving unprecedented power to examine diseases of the eye, retinal morphometry can give insights into the diseases of the vascular and neurological systems. The retina shares similar embryological origin, anatomical features and physiological properties with the brain, ${ }^{59}$ it offers an accessible site to investigate the central nervous system in vivo. ${ }^{60}$ Using fundus photographs, retinal microvascular morphometry offers the prospect of meaningful improvements in risk stratification in cardiovascular disease. ${ }^{61}$ Table 4 summarises major longitudinal cohort studies $(\mathrm{n}<10000)$ on an eye and systemic diseases that were performed among the Western populations ${ }^{62-68}$ and Asian populations. ${ }^{69-75}$ Early signs of elevated risk of major systemic diseases, such as diabetes mellitus, ${ }^{76}$ stroke, ${ }^{77-79}$ hypertension ${ }^{80}$ and cardiovascular diseases, ${ }^{81}$ can be detected in the retinal blood vessels. The advent of powerful computer-based algorithms offers the prospect of truly ground-breaking advances in medical care. ${ }^{37}$ A recent study demonstrated that the application of deep learning to retinal fundus images can be used to predict cardiovascular risk factors such as age, gender and smoking status. ${ }^{37}$

Neurodegenerative diseases including Parkinson's disease (PD), Alzheimer's disease ( $\mathrm{AD}$ ) and multiple sclerosis (MS) all have a measurable effect on the retina. Recent studies using OCT showed differences in inner retinal layers between the normal population and participants with $\mathrm{PD}^{82} \mathrm{AD}^{83}$ and MS. ${ }^{84}$ Studies have shown reduction in the ganglion cell layer along with the inner plexiform layer in patients with $\mathrm{AD}$ compared with healthy controls, ${ }^{85-87}$ while others reported thinning in the RNFL, especially in the superior and inferior quadrants. ${ }^{83}{ }^{88-90}$ With a large cohort and detailed measurements at multiple time points, the UK Biobank is able to assess if changes in the eye precede development of these conditions or are a consequence from the neurodegenerative conditions.

\section{Comparison with other cohorts, biobanks and consortia}

Table 5 describes large prospective cohorts $(>10000)$ that examine associations with eye diseases. European studies include the Rotterdam Study of 14926 participants aged 45 years or older ${ }^{91}$ and the Gutenberg Health Study of 14700 participants aged 35-74 years. ${ }^{92}$ In Asia, the Kangbuk Samsung Health Study performed health screening on 281238 employees aged 20 years and older. However, there are limited ocular measurements with the KSH study. ${ }^{93}$ Large prospective studies are well suited for investigating the risk factors for diseases and could either be conducted as a biobank such as the UK Biobank, ${ }^{22}$ China Kadoorie Biobank ${ }^{95}$ and The American Cancer Society's Cancer Prevention Study $3^{96}$ or a consortium such as the $\mathrm{P}_{3} \mathrm{G}$ consortium, ${ }^{97}$ National Cancer Institute Cohort Consortium, ${ }^{98}$ Cohorts for Heart and Aging Research in Genomic Epidemiology ${ }^{99}$ and European Eye Epidemiology (E3) consortium. However, eye measures are not available on most of these large prospective studies except the UK Biobank and E3 consortium. The major differences between the biobank design and consortia are that the latter are often developed by pooling data from different studies with disparate consent/governance 


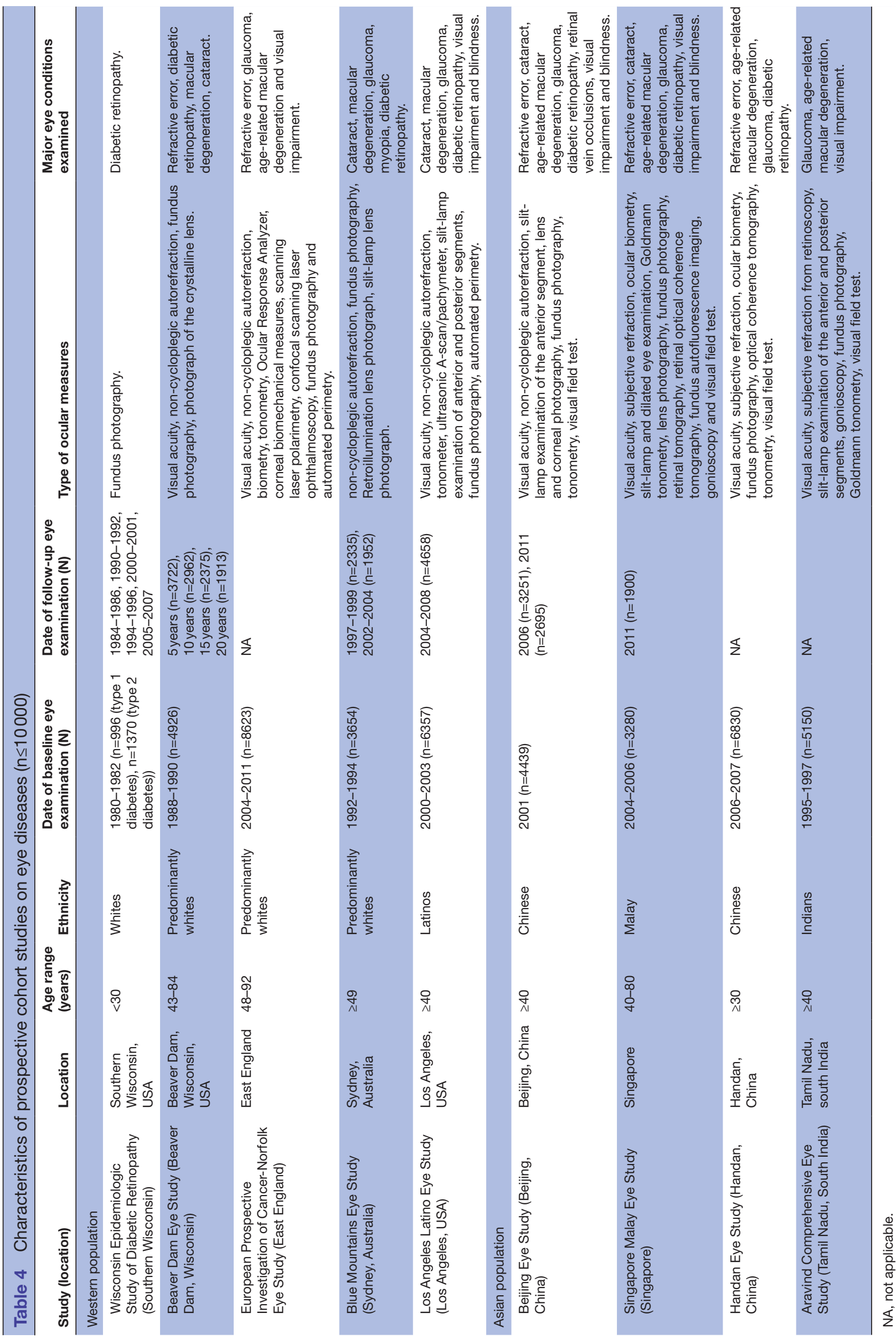




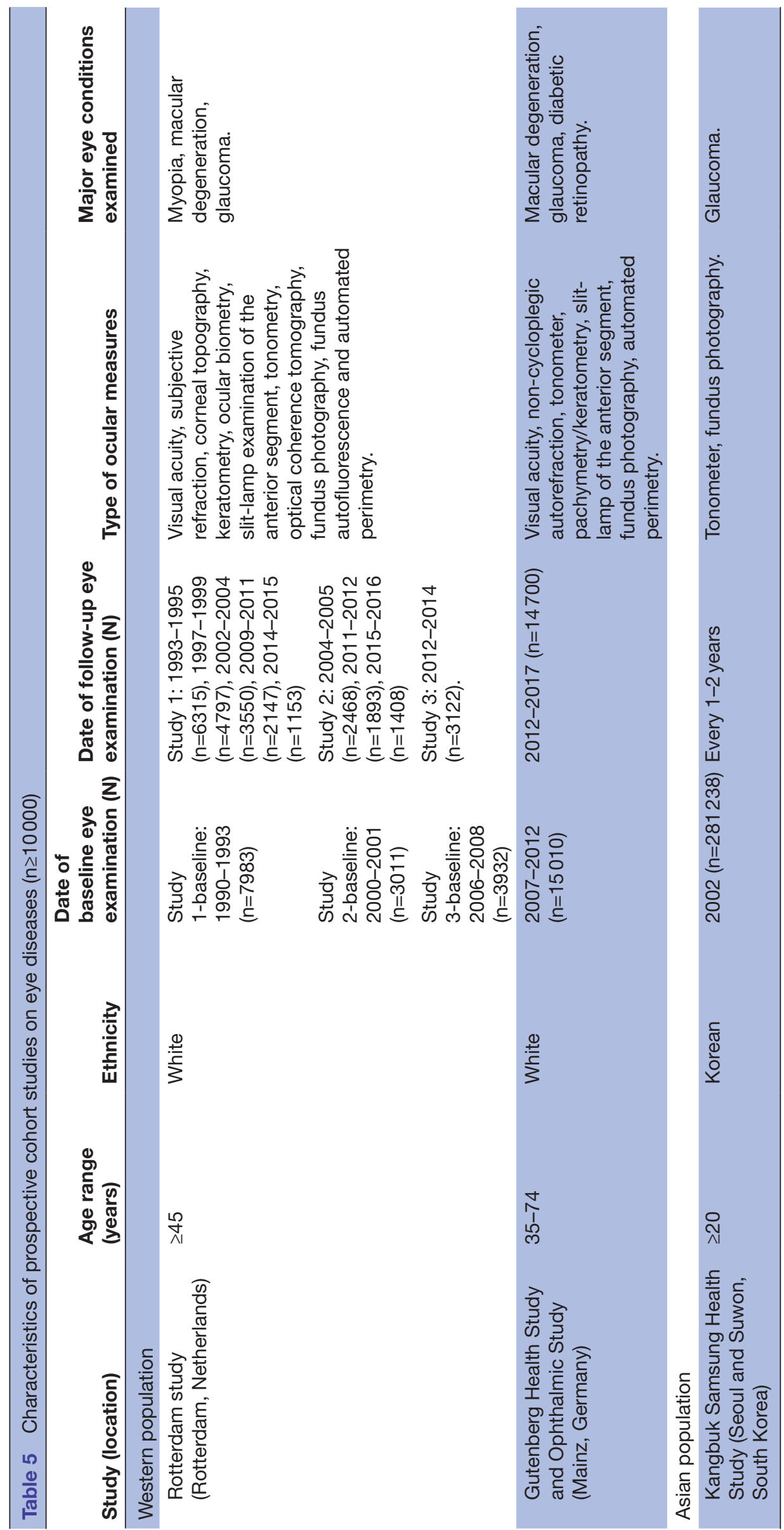


procedures that may limit the power to address previously unanticipated research questions. ${ }^{100}$ Moreover, there is more variability in sampling, measurements of exposures and identification of diseases ascertained. ${ }^{101} 102$ In contrast, biobanks are usually planned in advance with uniformity in collection of samples and genotyping has been carried out according to a predetermined strategy. Thus, consortia are typically regarded as less robust because of problems with direct and imputed genotyping, and non-standardised diagnostic criteria.

\section{Strengths and limitations}

UK Biobank is the only prospective study with a very large sample size $(>100000)$ of participants with a range of eye measures. With the projected number of new cases diagnosed with a range of eye diseases, it will allow researchers to investigate the genetic, environmental and lifestyle risk factors of various eye diseases. In addition, there are intensive methods to ascertain outcomes with electronic and semiautomated sources for validation and sub classification. ${ }^{20}$

Despite the scope of eye data collected in the UK Biobank, limitations exist within the study. One important limitation of UK Biobank was its low response rate $(5.5 \%)$, and that participants were more likely to be from a healthier, more affluent sector of the UK population. However, it is unlikely that the direction of the association is opposite in respondents and non-respondents, and hence representativeness is not a major concern. The UK Biobank was not set up to be representative of the general UK population. More importantly, the large sample size and extensive exposures allow for valid scientific inferences of associations between exposures and health outcomes that are generalisable to the wider population. In addition, a large number of cases allow the detection and quantification of small effect sizes. Eye measurements were performed in 6 out of 22 of the assessment centres and participants with eye measures tend to have an education level of degree and above compared with the whole UK Biobank cohort. Hence, they may come from a more affluent sector and may not represent the whole UK Biobank cohort. The first repeat eye measure was only performed in approximately 20000 participants. However, a repeat of the baseline visit will be conducted every few years in subsets of 20-25 000 participants. The self-reported nature of eye diseases may result in recall bias and misclassification error. However, the biases should be minimal as the ascertainment of outcomes will be conducted through linkages to national healthcare database, relevant administrative databases and analysis of available phenotypic data. We have access to medical records. ${ }^{32}$

\section{COLLABORATION}

UK Biobank aims to provide open access data for health-related research and the data are made available to all bona fide researchers from the academic, charity, public and commercial sectors, both in the UK and internationally, without preferential or exclusive access for any user. ${ }^{20}$ All interested researchers may apply to access the data via an online application. Strict guidelines are in place to help ensure anonymity and confidentiality of participants' data and samples. ${ }^{103}$

\section{CONCLUSION}

UK Biobank Eye and Vision data would allow investigation of the factors leading to the onset and disease progression of major eye diseases. In addition, the ocular phenotypes could be explored with systemic diseases such as diabetes, hypertension and neurological diseases. In conclusion, the extensive exposures and health outcomes available in the UK Biobank will provide scientists with insights into the predictors of ocular and systemic diseases, allowing customised treatment therapies and interventions tailored to the individual patient. Furthermore, its collaborative and multidisciplinary research allows scientists to use known or innovative methods to explore and further develop techniques and treatment strategies that could have a major impact on the field of biomedical, behavioural or clinical research.

Acknowledgements We would like to acknowledge Tim Sprosen, Alan Young, Sir Rory Collins (all Oxford University Clinical Trials Service Unit and Epidemiological Studies Unit) and all those who had contributed to design and development of the UK Biobank eye data resource.

Collaborators UK Biobank Eye \& Vision Consortium: The UK Biobank Eye \& Vision Consortium members are Tariq Aslam, PhD, Manchester University, Sarah A. Barman, PhD, Kingston University, Jenny H. Barrett, PhD, University of Leeds, Paul Bishop, PhD, Manchester University, Peter Blows, BSc, NIHR Biomedical Research Centre, Catey Bunce, DSc, King's College London, Roxana 0. Carare, PhD, University of Southampton, Usha Chakravarthy, FRCOphth, Queens University Belfast, Michelle Chan, FRCOphth, NIHR Biomedical Research Centre, Sharon Y.L. Chua, PhD, NIHR Biomedical Research Centre, David P. Crabb, PhD, UCL, Philippa M. Cumberland, MSc, UCL Great Ormond Street Institute of Child Health, Alexander Day,PhD, NIHR Biomedical Research Centre, Parul Desai, PhD, NIHRBiomedical Research Centre, Bal Dhillon, FRCOphth, University ofEdinburgh, Andrew D. Dick, FRCOphth, University of Bristol, Cathy Egan, FRCOphth, NIHR Biomedical Research Centre, Sarah Ennis, PhD, University of Southampton, Paul Foster, PhD, NIHR Biomedical ResearchCentre, Marcus Fruttiger, PhD, NIHR Biomedical Research Centre, John E.J. Gallacher, PhD, University of Oxford, David F. GARWAY-HEATH MD FRCOphth NIHR Biomedical Research Centre, Jane Gibson, PhD, University of Southampton, Dan Gore, FRCOphth, NIHR Biomedical Research Centre, Jeremy A. Guggenheim, $\mathrm{PhD}$, Cardiff University, Chris J. Hammond, FRCOphth, King's College London, Alison Hardcastle, PhD,NIHR Biomedical Research Centre, Simon P. Harding, MD, University of Liverpool, Ruth E. Hogg, PhD, Queens University Belfast, Pirro Hysi, PhD, King's College London, Pearse A. Keane, MD, NIHR, Biomedical Research Centre, Sir Peng T. Khaw, PhD, NIHR Biomedical Research Centre, Anthony P. Khawaja, DPhil, NIHR Biomedical Research Centre, Gerassimos Lascaratos, PhD, NIHR Biomedical Research Centre, AndrewJ. Lotery, MD, University of Southampton, TomMacGillivray, PhD, University of Edinburgh, Sarah Mackie, PhD, University of Leeds, Keith Martin, FRCOphth, University of Cambridge, Michelle McGaughey,Queen's University Belfast, Bernadette McGuinness, PhD, Queen'sUniversity Belfast, Gareth J. McKay, PhD, Queen's University Belfast, Martin McKibbin, FRCOphth, Leeds Teaching Hospitals NHS Trust, Danny Mitry, PhD, NIHR Biomedical Research Centre, Tony Moore, FRCOphth, NIHR Biomedical Research Centre, James E. Morgan, DPhil, Cardiff University, Zaynah A. Muthy, BSc, NIHR Biomedical Research Centre, Eoin O'Sullivan, MD, King's College Hospital NHS Foundation Trust,Chris G. Owen, PhD, University of London, Praveen Patel, FRCOphth, NIHR Biomedical Research Centre, Euan Paterson, BSc, Queens University Belfast, Tunde Peto, PhD, Queen's University Belfast, Axel Petzold, PhD, UCL, Jugnoo S. Rahi, PhD, UCL Great Ormond Street Institute of Child Health, Alicja R. Rudnikca, PhD, University ofLondon, Jay Self, $\mathrm{PhD}$, University of Southampton, Sobha Sivaprasad, FRCOphth, NIHR Biomedical 
Research Centre, David Steel, FRCOphth, Newcastle University, Irene Stratton, MSc, Gloucestershire Hospitals NHS Foundation Trust, Nicholas Strouthidis, PhD, NIHR Biomedical Research Centre, Cathie Sudlow, DPhil, University of Edinburgh, Dhanes Thomas, FRCOphth, NIHR Biomedical Research Centre, Emanuele Trucco, PhD, University of Dundee, Adnan Tufail, FRCOphth, NIHR Biomedical Research Centre, Veronique Vitart, PhD, University of Edinburgh, Stephen A. Vernon, DM, Nottingham University Hospitals NHSTrust, Ananth C. Viswanathan, FRCOphth, NIHR Biomedical Research Centre, Cathy Williams, PhD, University of Bristol, Katie Williams, PhD King's College London, Jayne V. Woodside, MRCOphth, PhD, Queen's University Belfast, Max M. Yates, PhD, University of East Anglia, Jennifer Yip, PhD, University of Cambridge, and Yalin Zheng, PhD, University of Liverpool.

Contributors SYLC had full access to all the data in the study and took responsibility for the integrity of the data and accuracy of the data analysis. Concept and design: NA, AL, CS, PTK and PJF. Acquisition, analysis or interpretation of data: SYLC, DT, NA, AL, PD, PP, ZM, CS, TP, PTK and PJF. Critical revision of the manuscript for important intellectual content: all authors. Obtained funding: CS, PP, PTK, PJF and UK Biobank Eye and Vision Consortium. All authors read and critically revised the manuscript. All authors approved the final manuscript.

Funding The UK Biobank Eye and Vision Consortium is supported by grants from Moorfields Eye Charity, The NIHR Biomedical Research Centre at Moorfields Eye Hospital NHS Foundation Trust (BRC2_009) and UCL Institute of Ophthalmology and the Alcon Research Institute.

Disclaimer No funders had a direct role in the collection, management, analysis or interpretation of the data; preparation, review or approval of the manuscript; nor in the decision to submit the manuscript for publication.

Competing interests This analysis was supported by the Eranda Foundation via the International Glaucoma Association in the design and conduct of the study. The UCL ORS and GRS programmes provided scholarship support for ZM, PTK, PJF, and PP and SYLC received salary support from the NIHR BRC at Moorfields Eye Hospital. PJF received support from the Richard Desmond Charitable Trust, via Fight for Sight, London. PJF reports personal fees from Allergan, Carl Zeiss, Google/ DeepMind and Santen, a grant from Alcon, outside the submitted work.

\section{Patient consent Obtained.}

Ethics approval The North West Multi-center Research Ethics Committee approved the study (reference no., 06/MRE08/65), in accordance with the tenets of the Declaration of Helsinki. Detailed information about the study is available at the UK Biobank web site (https://www.ukbiobank.ac.uk).

Provenance and peer review Not commissioned; externally peer reviewed.

Data sharing statement This research used data from the UK Biobank Resource, under data access request number 2112 .

Open access This is an open access article distributed in accordance with the Creative Commons Attribution Non Commercial (CC BY-NC 4.0) license, which permits others to distribute, remix, adapt, build upon this work non-commercially, and license their derivative works on different terms, provided the original work is properly cited, appropriate credit is given, any changes made indicated, and the use is non-commercial. See: http://creativecommons.org/licenses/by-nc/4.0/.

\section{REFERENCES}

1. Niccoli T, Partridge L. Ageing as a risk factor for disease. Curr Biol 2012;22:R741-R752

2. Organization WH. World report on ageing and health world health organization. $2015 \mathrm{http}: / /$ www.who.int/ageing/publications/worldreport-2015/en/.

3. Bommer C, Heesemann E, Sagalova V, et al. The global economic burden of diabetes in adults aged 20-79 years: a cost-of-illness study. Lancet Diabetes Endocrinol 2017;5:423-30.

4. de Voogd S, Ikram MK, Wolfs RC, et al. Incidence of open-angle glaucoma in a general elderly population: the Rotterdam Study. Ophthalmology 2005;112:1487-93.

5. Leske MC, Heijl A, Hyman L, et al. Predictors of long-term progression in the early manifest glaucoma trial. Ophthalmology 2007;114:1965-72

6. Chan MP, Grossi CM, Khawaja AP, et al. Associations with intraocular pressure in a large cohort: Results from the UK Biobank. Ophthalmology 2016;123:771-82.

7. Keane PA, Grossi CM, Foster PJ, et al. Optical coherence tomography in the uk biobank study - rapid automated analysis of retinal thickness for large population-based studies. PLoS One 2016;11:e0164095.

8. Adhi M, Duker JS. Optical coherence tomography-current and future applications. Curr Opin Ophthalmol 2013;24:213-21.

9. Williams GP, Pathak-Ray V, Austin MW. The social impact of visual impairment. Br J Ophthalmol 2007;91:986.

10. Köberlein J, Beifus K, Schaffert C, et al. The economic burden of visual impairment and blindness: a systematic review. BMJ Open 2013;3:e003471.

11. Lander ES, Linton LM, Birren B, et al. Initial sequencing and analysis of the human genome. Nature 2001;409:860-921.

12. Gemenetzi M, Yang Y, Lotery AJ. Current concepts on primary open-angle glaucoma genetics: a contribution to disease pathophysiology and future treatment. Eye 2012;26:355-69.

13. Black JRM, Clark SJ. Age-related macular degeneration: genomewide association studies to translation. Genetics in Medicine 2016;18:283-9.

14. Fritsche LG, IgI W, Bailey JNC, et al. A large genome-wide association study of age-related macular degeneration highlights contributions of rare and common variants. Nat Genet 2016;48:134-43.

15. Ottman R. Gene-environment interaction: definitions and study designs. Prev Med 1996;25:764-70.

16. Tan Y-D, Fornage M, George V, et al. Parent-child pair design for detecting gene-environment interactions in complex diseases. Hum Genet 2007;121:745-57.

17. Song JW, Chung KC. Observational studies: cohort and casecontrol studies. Plast Reconstr Surg 2010;126:2234-42.

18. Collins FS. The case for a US prospective cohort study of genes and environment. Nature 2004;429:475-7.

19. Manolio TA, Bailey-Wilson JE, Collins FS. Genes, environment and the value of prospective cohort studies. Nat Rev Genet 2006;7:812-20.

20. Sudlow C, Gallacher J, Allen N, et al. UK biobank: an open access resource for identifying the causes of a wide range of complex diseases of middle and old age. PLoS Med 2015;12:e1001779.

21. Allen N, Sudlow C, Downey P, et al. UK Biobank: Current status and what it means for epidemiology. Health Policy Technol 2012;1:123-6.

22. . UK Biobank. 2018. updated 2018. Available from: http://www. ukbiobank.ac.uk/

23. Bycroft C, Freeman C, Petkova D, et al. Genome-wide genetic data on 500,000 UK Biobank participants. bioRxiv, 2017.

24. Miller KL, Alfaro-Almagro F, Bangerter NK, et al. Multimodal population brain imaging in the UK Biobank prospective epidemiological study. Nat Neurosci 2016;19:1523-36.

25. Standard B. Test charts for determining distance visual acuity: BS 4274-1968: London British Standards Institute, 1968.

26. Cumberland PM, Bao Y, Hysi PG, et al. Frequency and distribution of refractive error in adult life: Methodology and findings of the UK biobank study. PLoS One 2015;10:e0139780.

27. Luce DA. Determining in vivo biomechanical properties of the cornea with an ocular response analyzer. Journal of Cataract \& Refractive Surgery 2005;31:156-62.

28. Garcia-Porta N, Fernandes P, Queiros A, et al. Corneal biomechanical properties in different ocular conditions and new measurement techniques. ISRN Ophthalmol 2014;2014:1-19.

29. Medeiros FA, Weinreb RN. Evaluation of the influence of corneal biomechanical properties on intraocular pressure measurements using the ocular response analyzer. J Glaucoma 2006;15:364-70.

30. Patel PJ, Foster PJ, Grossi CM, et al. Spectral-domain optical coherence tomography imaging in 67321 adults: Associations with macular thickness in the UK Biobank study. Ophthalmology 2016;123:829-40.

31. . Topcon. Optical Coherence Tomography 3D OCT-1000

32. Desai P, Minassian DC, Reidy A, et al. Number of incident cases of the main eye diseases of ageing in the UK Biobank cohort, projected over a 25 -year period from time of recruitment. $\mathrm{Br} J$ Ophthalmol 2018:1-5.

33. Guggenheim JA, Williams C. UK Biobank Eye and Vision Consortium. Role of Educational Exposure in the Association Between Myopia and Birth Order. JAMA Ophthalmol 2015;133:1408-14.

34. Rudnicka AR, Owen CG, Richards M, et al. Effect of breastfeeding and sociodemographic factors on visual outcome in childhood and adolescence. Am J Clin Nutr 2008:87:1392-9.

35. Guggenheim JA, McMahon G, Northstone K, et al. Birth order and myopia. Ophthalmic Epidemiol 2013;20:375-84.

36. Ko F, Muthy ZA, Gallacher J, et al. Association of Retinal Nerve Fiber Layer Thinning With Current and Future Cognitive Decline: A Study Using Optical Coherence Tomography. JAMA Neurol 2018;75:1198-1205. 
37. Poplin R, Varadarajan AV, Blumer K, et al. Prediction of cardiovascular risk factors from retinal fundus photographs via deep learning. Nat Biomed Eng 2018;2:158-64.

38. World Health Organization. Prevention of blindness and visual impairment. http://www.who.int/blindness/causes/en/

39. Clemons TE, Milton RC, Klein R, et al. 3rd. Risk factors for the incidence of Advanced Age-Related Macular Degeneration in the Age-Related Eye Disease Study (AREDS) AREDS report no. 19. Ophthalmology 2005;112:533-9.

40. Heiba IM, Elston RC, Klein BEK, et al. Sibling correlations and segregation analysis of age-related maculopathy: The beaver dam eye study. Genet Epidemiol 1994;11:51-67.

41. Klaver CC, Wolfs RC, Assink JJ, et al. Genetic risk of age-related maculopathy. Population-based familial aggregation study. Archives of ophthalmology 1998;116:1646-51.

42. Schaumberg DA, Hankinson SE, Guo Q, et al. A prospective study of 2 major age-related macular degeneration susceptibility alleles and interactions with modifiable risk factors. Arch Ophthalmol 2007;125:55-62.

43. Hattersley AT, McCarthy MI. What makes a good genetic association study?. Lancet 2005;366:1315-23.

44. Weih LM, Nanjan M, McCarty CA, et al. Prevalence and predictors of open-angle glaucoma: results from the visual impairment project. Ophthalmology 2001;108:1966-72.

45. Mitchell P, Smith W, Attebo K, et al. Prevalence of openangle glaucoma in Australia. The Blue Mountains Eye Study. Ophthalmology 1996;103:1661-9.

46. Tielsch JM, Sommer A, Katz J, et al. Racial variations in the prevalence of primary open-angle glaucoma. The Baltimore Eye Survey. JAMA 1991;266:369-74.

47. Klein BE, Klein R, Sponsel WE, et al. Prevalence of glaucoma. The Beaver Dam Eye Study. Ophthalmology 1992;99:1499-504.

48. Chua J, Baskaran M, Ong PG, et al. Prevalence, risk factors, and visual features of undiagnosed glaucoma: The singapore epidemiology of eye diseases study. JAMA Ophthalmol 2015;133:938-46.

49. Vijaya L, George R, Baskaran M, et al. Prevalence of primary open-angle glaucoma in an urban south Indian population and comparison with a rural population. The Chennai Glaucoma Study. Ophthalmology 2008;115:648-54.

50. Song W, Shan L, Cheng F, et al. Prevalence of glaucoma in a rural northern china adult population: a population-based survey in kailu county, inner mongolia. Ophthalmology 2011;118:1982-8.

51. Varma R, Mohanty SA, Deneen J, et al. Burden and predictors of undetected eye disease in Mexican-Americans: the Los Angeles Latino Eye Study. Med Care 2008;46:497-506.

52. Chua J, Lim B, Fenwick EK, et al. Prevalence, risk factors, and impact of undiagnosed visually significant cataract: The singapore epidemiology of eye diseases study. PLoS One 2017;12:e0170804.

53. Linton KL, Klein BE, Klein R. The validity of self-reported and surrogate-reported cataract and age-related macular degeneration in the Beaver Dam Eye Study. Am J Epidemiol 1991;134:1438-46.

54. Klein R, Klein BE, Moss SE, et al. The validity of a survey question to study diabetic retinopathy. Am J Epidemiol 1986;124:104-10.

55. Patty L, Wu C, Torres M, et al. Validity of self-reported eye disease and treatment in a population-based study: the Los Angeles Latino Eye Study. Ophthalmology 2012;119:1725-30.

56. Shweikh Y, Ko F, Chan MP, et al. Measures of socioeconomic status and self-reported glaucoma in the U.K. Biobank cohort. Eye 2015;29:1360-7.

57. Wensor MD, McCarty CA, Stanislavsky YL, et al. The prevalence of glaucoma in the melbourne visual impairment project. Ophthalmology 1998:105:733-9.

58. Bonomi L, Marchini G, Marraffa M, et al. Prevalence of glaucoma and intraocular pressure distribution in a defined population. The Egna-Neumarkt Study. Ophthalmology 1998;105:209-15.

59. Patton N, Aslam T, Macgillivray T, et al. Retinal vascular image analysis as a potential screening tool for cerebrovascular disease: a rationale based on homology between cerebral and retinal microvasculatures. J Anat 2005;206:319-48.

60. London A, Benhar I, Schwartz M. The retina as a window to the brain-from eye research to CNS disorders. Nat Rev Neurol 2013;9:44-53

61. Welikala RA, Foster PJ, Whincup PH, et al. Automated arteriole and venule classification using deep learning for retinal images from the UK Biobank cohort. Comput Biol Med 2017;90:23-32.

62. Klein R, Knudtson MD, Lee KE, et al. The Wisconsin Epidemiologic Study of Diabetic Retinopathy XXIII: the twenty-five-year incidence of macular edema in persons with type 1 diabetes. Ophthalmology 2009;116:497-503.
63. Joachim N, Mitchell P, Burlutsky G, et al. The incidence and progression of age-related macular degeneration over 15 years: The blue mountains eye study. Ophthalmology 2015;122:2482-9.

64. Kanthan GL, Wang JJ, Rochtchina E, et al. Ten-year incidence of age-related cataract and cataract surgery in an older Australian population. The Blue Mountains Eye Study. Ophthalmology 2008:115:808-14

65. Klein BE, Howard KP, Lee KE, et al. The relationship of cataract and cataract extraction to age-related macular degeneration: the Beaver Dam Eye Study. Ophthalmology 2012;119:1628-33.

66. Chan MPY, Broadway DC, Khawaja AP, et al. Glaucoma and intraocular pressure in EPIC-Norfolk Eye Study: cross sectional study. BMJ 2017;358:j3889.

67. Varma R, Chung J, Foong AW, et al. Four-year incidence and progression of visual impairment in Latinos: the Los Angeles Latino Eye Study. Am J Ophthalmol 2010;149:713-27.

68. Choudhury F, Varma R, Klein R, et al. Age-related macular degeneration and quality of life in latinos: The los angeles latino eye study. JAMA Ophthalmol 2016;134:683-90.

69. You QS, Xu L, Yang $\mathrm{H}$, et al. Five-year incidence of visual impairment and blindness in adult Chinese the Beijing Eye Study. Ophthalmology 2011;118:1069-75.

70. Wang YX, Xu L, Yang H, et al. Prevalence of glaucoma in North China: the Beijing Eye Study. Am J Ophthalmol 2010;150:917-24.

71. Foong AW, Saw SM, Loo JL, et al. Rationale and methodology for a population-based study of eye diseases in Malay people: The Singapore Malay eye study (SiMES). Ophthalmic Epidemiol 2007:14:25-35.

72. Rosman M, Zheng Y, Wong W, et al. Singapore Malay Eye Study: rationale and methodology of 6-year follow-up study (SiMES-2). Clin Exp Ophthalmol 2012;40:557-68.

73. Gao J, Liang Y, Wang $\mathrm{F}$, et al. Retinal vessels change in primary angle-closure glaucoma: the Handan Eye Study. Sci Rep 2015;5:9585.

74. Wang FH, Liang YB, Zhang F, et al. Prevalence of diabetic retinopathy in rural China: the Handan Eye Study. Ophthalmology 2009;116:461-7.

75. Ramakrishnan R, Nirmalan PK, Krishnadas R, et al. Glaucoma in a rural population of southern India. Ophthalmology 2003;110:1484-90.

76. Cheung N, Mitchell P, Wong TY. Diabetic retinopathy. The Lancet 2010;376:124-36

77. Baker ML, Hand PJ, Wang JJ, et al. Retinal signs and stroke: revisiting the link between the eye and brain. Stroke 2008;39:1371-9.

78. Cheung CY, Tay WT, Ikram MK, et al. Retinal microvascular changes and risk of stroke: the Singapore Malay Eye Study. Stroke 2013;44:2402-8.

79. Ikram MK, de Jong FJ, Bos MJ, et al. Retinal vessel diameters and risk of stroke: the Rotterdam Study. Neurology 2006;66:1339-43.

80. Wong T, Mitchell P. The eye in hypertension. The Lancet 2007:369:425-35

81. McGeechan K, Liew G, Macaskill P, et al. Meta-analysis: retinal vessel caliber and risk for coronary heart disease. Ann Intern Med 2009;151:404-13.

82. Lee JY, Ahn J, Kim TW, et al. Optical coherence tomography in Parkinson's disease: is the retina a biomarker? J Parkinsons Dis 2014;4:197-204.

83. Coppola G, Di Renzo A, Ziccardi L, et al. Optical coherence tomography in alzheimer's disease: A meta-analysis. PLoS One 2015;10:e0134750

84. Garcia-Martin E, Ara JR, Martin J, et al. Retinal and optic nerve degeneration in patients with multiple sclerosis followed up for 5 Years. Ophthalmology 2017;124:688-96.

85. Cheung CY, Ong YT, Hilal S, et al. Retinal ganglion cell analysis using high -definition optical coherence tomography in patients with mild cognitive impairment and Alzheimer's disease. J Alzheimers Dis 2015:45:45-56.

86. Cunha LP, Lopes LC, Costa-Cunha LV, et al. Macular thickness measurements with frequency domain-oct for quantification of retinal neural loss and its correlation with cognitive impairment in Alzheimer's disease. PLoS One 2016;11:e0153830.

87. Ferrari L, Huang SC, Magnani G, et al. Optical coherence tomography reveals retinal neuroaxonal thinning in frontotemporal dementia as in alzheimer's disease. J Alzheimers Dis 2017:56:1101-7.

88. Ascaso FJ, Cruz N, Modrego PJ, et al. Retinal alterations in mild cognitive impairment and Alzheimer's disease: an optical coherence tomography study. J Neurol 2014;261:1522-30.

89. Garcia-Martin E, Satue M, Fuertes I, et al. Ability and reproducibility of Fourier-domain optical coherence tomography to detect retinal 
nerve fiber layer atrophy in Parkinson's disease. Ophthalmology 2012:119:2161-7

90. Cunha LP, Almeida AL, Costa-Cunha LV, et al. The role of optical coherence tomography in Alzheimer's disease. Int $J$ Retina Vitreous 2016;2:24

91. Ikram MA, Brusselle GGO, Murad SD, et al. The Rotterdam Study: 2018 update on objectives, design and main results. Eur J Epidemiol 2017;32:807-50.

92. Höhn R, Kottler U, Peto T, et al. The ophthalmic branch of the Gutenberg Health Study: study design, cohort profile and selfreported diseases. PLoS One 2015;10:e0120476.

93. Zhao D, Kim MH, Pastor-Barriuso R, et al. A longitudinal study of age-related changes in intraocular pressure: the Kangbuk Samsung Health Study. Invest Ophthalmol Vis Sci 2014;55:6244-50.

94. Zhao D, Kim MH, Pastor-Barriuso R, et al. A longitudinal study of association between adiposity markers and intraocular pressure: The kangbuk samsung health study. PLoS One 2016;11:e0146057.

95. Chen Z, Chen J, Collins R, et al. China Kadoorie Biobank of 0.5 million people: survey methods, baseline characteristics and longterm follow-up. Int J Epidemiol 2011;40:1652-66.
96. Patel AV, Jacobs EJ, Dudas DM, et al. The american cancer society's Cancer Prevention study 3 (CPS-3): Recruitment, study design, and baseline characteristics. Cancer 2017;123:2014-24.

97. Ouellette S, Tassé AM. P(3)G - 10 years of toolbuilding: From the population biobank to the clinic. Appl Trans/ Genom 2014;3:36-40.

98. National Cancer institute Cohort Consortium. 2017. Available from: https://epi.grants.cancer.gov/Consortia/cohort.html

99. Psaty BM, O'Donnell CJ, Gudnason V, et al. CHARGE Consortium. Cohorts for Heart and Aging Research in Genomic Epidemiology (CHARGE) Consortium: Design of prospective meta-analyses of genome-wide association studies from 5 cohorts. Circ Cardiovasc Genet 2009;2:73-80

100. Bovenberg JA. Property rights in blood, genes \& data naturally yours? Portland: Ringgold Inc, 2006

101. Willett WC, Blot WJ, Colditz GA, et al. Merging and emerging cohorts: not worth the wait. Nature 2007;445:257-8.

102. Collins FS, Manolio TA. Merging and emerging cohorts: necessary but not sufficient. Nature 2007:445:259.

103. UK Biobank. Access Procedures: application and review procedures for access to the UK Biobank Resource. http://www. ukbiobank.ac.uk/resources/ 